\title{
Long-term effects of partial limb amputation in man
}

\author{
A. J. M c COMAS, R. E.P. S I C A A N D S. B A NER JEE \\ From the Departments of Medicine and Rehabilitation, McMaster University Medical Centre, \\ Hamilton, Ontario, Canada
}

SUMMARY Ten patients with amputation of part of one arm have been studied electrophysiologically. In each patient the ulnar nerve was stimulated electrically in the amputation stump and at a corresponding level in the intact limb. Control observations were also made on 15 normal subjects. In the partially-amputated (PA) limbs the amplitudes of the centripetal ulnar nerve compound action potentials, after maximal stimulation of fast-conducting fibres, were markedly reduced in comparison with the results in control limbs. A small decrease in the mean impulse conduction velocity was observed in the population of PA limbs. In comparison with control observations, stimulation of the ulnar nerve in a PA limb evoked responses in the contralateral somatosensory cortex which were significantly diminished. Stimulation of PA limbs caused reflex excitation and inhibition of triceps motoneurones similar to that observed in control subjects. In the intact limbs of the amputees, however, inhibition was reduced, possibly as a consequence of overuse. It is concluded that the receipt of an input from the periphery is essential for the functional integrity of most motor and sensory nerve axons, and probably for fibres in the dorsal column-medial lemniscus pathway.

One well-tried approach to the study of neurotrophic phenomena is to observe the changes which ensue when one population of neurones is deprived of its synaptic linkage with another or, in the case of the peripheral nervous system, when the connections with the periphery are severed. It is already evident that among the factors affecting the outcome of such experiments are the species and age of the experimental animal, the nature and duration of the disruption, and the neural system under study (for review see Drachman, 1974). In view of such variability it is still necessary to consider new evidence on particular populations of neurones. In the present study we have attempted to delineate some of the central effects which follow amputation of part of a human limb. Apart from the interest afforded by studies of man, there is the possibility of being able to examine the results of lesions of many years duration. A further advantage, common to all amputation studies, is that the removal of limb tissue prevents any complications caused by reinnervation. A brief account of this work has been given elsewhere (McComas et al., 1978).

Address for correspondence and reprint requests: Dr Alan J. McComas, Room 4U7, McMaster University Medical Centre, 1200 Main St. West, Hamilton, Ontario, Canada L8S 4J9.

Accepted 13 December 1977

\section{Subjects and methods}

Experiments were performed on 10 patients, nine of whom had previously undergone amputation of part of one arm. In eight instances the operation had been performed below the elbow; the length of the stump below the tip of the olecranon was measured in each case (Table 1). In one patient there was a congenital absence of the forearm and hand on one side. All the patients were males; their ages ranged from 11 to 47 years, and the amputations had been performed from four months to 30 years previously. In one patient who had undergone elective surgical amputation four months before study (JD, Table 1) it is probable that the median and ulnar nerves had been divided completely by a penetrating injury to the forearm two years previously. Control studies were performed on 10 normal males of similar ages, and additional observations were made on five healthy women. Informed consent was obtained from each subject for the experiment; approval was obtained from the Ethics Committee of the Research Advisory Group at McMaster University.

STIMULATING AND RECORDING TECHNIQUES Surface electrodes were used throughout and the experiments were conducted on both sides. 
Table 1 Main features of limb amputations in patients. The patient indicated by asterisk also had evidence of contralateral cervical root injury

\begin{tabular}{|c|c|c|c|c|c|}
\hline \multirow[b]{2}{*}{ Patient } & \multirow[b]{2}{*}{$\begin{array}{l}\text { Age } \\
(y r)\end{array}$} & \multicolumn{4}{|c|}{ Amputation } \\
\hline & & Side & $\begin{array}{l}\text { Duration } \\
(y r)\end{array}$ & $\begin{array}{l}\text { Stump } \\
\text { length } \\
\text { (cm below } \\
\text { elbow) }\end{array}$ & Cause \\
\hline JD & 45 & $\mathbf{R}$ & $(0.3)$ & 11 & $\begin{array}{l}\text { Volkmann's } \\
\text { disease } 2 \text { yr after } \\
\text { forearm injury } \\
\text { (? nerve section) }\end{array}$ \\
\hline WB & 28 & $\mathbf{L}$ & 2 & 17 & $\begin{array}{l}\text { Factory } \\
\text { machinery }\end{array}$ \\
\hline $\mathbf{K B}$ & 22 & $\mathbf{R}$ & 3 & 11 & $\begin{array}{l}\text { Gangrene after } \\
\text { intra-arterial } \\
\text { drug injection }\end{array}$ \\
\hline SK & 32 & $\mathbf{R}$ & 3 & 28 & $\begin{array}{l}\text { Dynamite injury } \\
\text { to hand }\end{array}$ \\
\hline NP & 11 & $\mathbf{L}$ & 6 & 12 & Lawnmower \\
\hline FE & 30 & $\overline{\mathbf{R}}$ & 6 & 25 & Car accident \\
\hline HB & 47 & $\mathbf{L}$ & 8 & $\begin{array}{l}15 \\
\text { (below } \\
\text { shoulder) }\end{array}$ & Dynamite \\
\hline WC & 31 & $\mathbf{R}$ & 14 & 28 & Car accident \\
\hline DB & 19 & $\mathbf{L}$ & 19 & 12 & $\begin{array}{l}\text { Congenital } \\
\text { anomaly }\end{array}$ \\
\hline PS & 35 & $\mathbf{L}$ & 30 & 19 & Explosion \\
\hline
\end{tabular}

\section{STIMULATION}

The ulnar nerve was stimulated using two chlorided silver discs mounted in a Plexiglass holder and coated with a conducting cream; the discs were $10 \mathrm{~mm}$ in diameter and their centres were separated by $30 \mathrm{~mm}$. The cathodal electrode was placed approximately $40 \mathrm{~mm}$ from the tip of the amputation stump while the anode was situated distally. The stimuli were rectangular voltage pulses, $50 \mu$ s in duration, delivered at $0.7 \mathrm{~Hz}$ from a Devices Ltd type 3072 stimulator; the latter was triggered from a Devices Ltd digitimer, model 3290.

\section{RECORDINGS}

\section{Peripheral nerve}

A pair of chlorided silver electrodes, similar to those used for stimulation (see above), were used to record the ascending compound action potential in the ulnar nerve approximately midway between the elbow and axilla. A lead plate, $30 \mathrm{~mm}$ square, was attached over the antecubital fossa and served as an earth (ground). In one patient recordings were also made from the median nerve. In the patient with an above-elbow amputation, the ulnar nerve was stimulated in the upper arm and recordings were made from the supraclavicular fossa.

\section{Somatosensory cortex}

On each side of the head a stigmatic electrode was attached to the scalp at a site $70 \mathrm{~mm}$ from the midline along an imaginary line drawn from a point $25 \mathrm{~mm}$ posterior to the vertex to the external auditory meatus; this site was judged to be the region for hand representation in the somatosensory cortex (see Giblin, 1964). A reference electrode was placed $70 \mathrm{~mm}$ anteriorly. The electrodes were chlorided silver cups, $80 \mathrm{~mm}$ in diameter, which were filled with a conducting cream and attached to the scalp with collodion. A similar electrode was placed over the centre of the forehead and served as an earth (ground).

\section{Triceps}

A pair of chlorided silver discs similar to those used for stimulating and recording from nerve (see above) was placed over the long head of the triceps muscle. Evoked activity was fed into amplifiers having flat frequency responses between $5 \mathrm{~Hz}$ and $1 \mathrm{kHz}$ for peripheral nerve and triceps recordings; for cortical recordings frequencies above $300 \mathrm{~Hz}$ were attenuated. The signals were displayed on a variable persistence storage oscilloscope (Hewlett-Packard (HP) 141B) and simultaneously averaged (HP signal analyser type 54808B). For nerve recordings eight responses were averaged while for the cortex either 32 or 64 potentials were used, depending on the degree of relaxation achieved by the subject.

The extent of excitation and inhibition in triceps motor units was measured from the averaged record of the rectified volitional activity by the technique of Caccia et al. (1973). Thus the separation between the initial horizontal segment of control volitional activity (0-30 ms poststimulus) and the baseline (no activity) served as a reference. The maximum amounts by which the reflexly elicited activity exceeded, or failed to reach, the control level were expressed as percentages of the latter and represented the intensities of excitation and inhibition respectively. Usually 32 responses were averaged.

\section{Results}

\section{PERIPHERAL NERVE RECORDINGS}

In normal subjects the peak-to-peak amplitudes of the compound action potentials in the ulnar nerves, after maximal stimulation of fastconducting fibres, ranged from 35 to $125 \mu \mathrm{V}$ (mean $71 \pm 27 \mu \mathrm{V}$ ). Similar values were obtained for the normal limbs of most amputees (mean amplitude $66 \pm 34 \mu \mathrm{V}$ ). In one patient (FE, Table 1), however, there was electrophysiological evidence that some cervical nerve roots had been damaged on the side of the intact limb as a result of a severe car accident; in this patient the action 


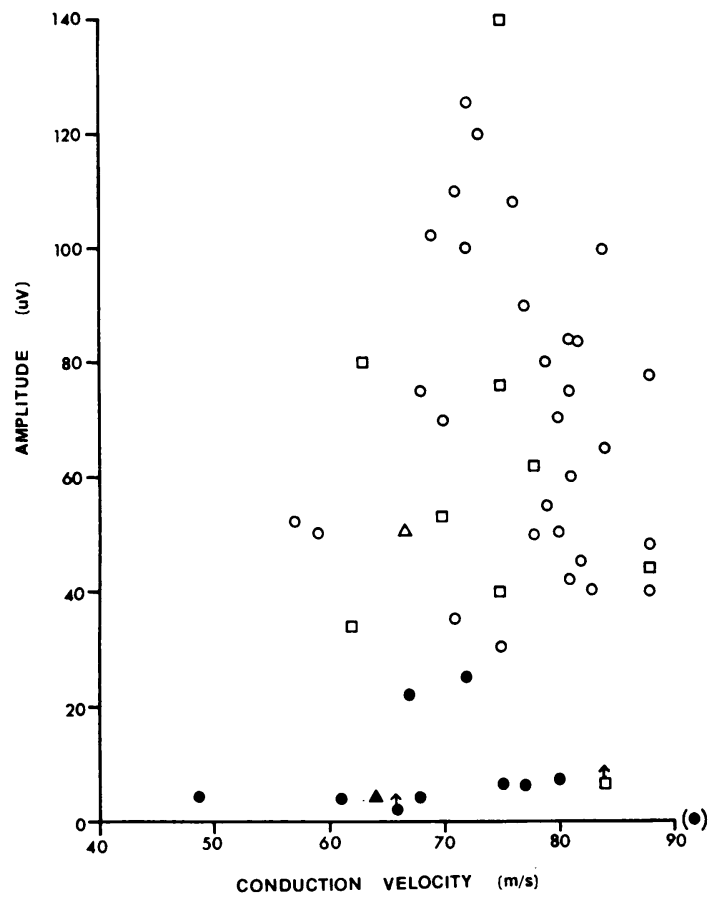

Fig. 1 Maximum action potential amplitudes and impulse velocities of ulnar nerves in PA (•) and intact ( $\square$ ) limbs of patients, and in arms of control subjects $(\bigcirc)$. Also shown are values for intact $(\triangle)$ and sectioned $(\Delta)$ median nerves of patient $S K$. Results with arrows are recordings made in supraclavicular fossae of patient $H B$.

Table 2 Mean amplitudes and conduction velocities of centripetally conducted ulnar nerve compound action potentials, after maximal stimulation of fast-conducting fibres. In the two right hand columns the significance levels refer to comparisons with pooled results from right $(R)$ and left $(L)$ control limbs; the levels of significance were calculated by Student's $t$ test. PA, I denote partially-amputated and intact limbs respectively

\begin{tabular}{|c|c|c|c|c|c|c|}
\hline & & \multicolumn{3}{|c|}{ Controls } & \multicolumn{2}{|l|}{ Patients } \\
\hline & & $R$ & $L$ & $R+L$ & $P A$ & $I$ \\
\hline Amplitude $(\mu \mathrm{V})$ & $\begin{array}{l}\bar{x} \\
\text { SD } \\
n \\
p\end{array}$ & $\begin{array}{l}70.7 \\
28.0 \\
15\end{array}$ & $\begin{array}{l}71.5 \\
26.5 \\
15\end{array}$ & $\begin{array}{l}71.1 \\
26.8 \\
30\end{array}$ & $\begin{array}{l}8.7 \\
8.6 \\
9 \\
<0.001\end{array}$ & $\begin{array}{c}66.1 \\
34.1 \\
8 \\
>0.5\end{array}$ \\
\hline $\begin{array}{l}\text { Conduction } \\
\text { velocity }(\mathrm{m} / \mathrm{s})\end{array}$ & $\begin{array}{l}\bar{x} \\
\text { SD } \\
n \\
p\end{array}$ & $\begin{array}{c}76.9 \\
7.6 \\
15\end{array}$ & $\begin{array}{c}77.0 \\
7.9 \\
15\end{array}$ & $\begin{array}{c}76.9 \\
7.6 \\
30\end{array}$ & $\begin{array}{l}68.2 \\
9.6 \\
9 \\
<0.02\end{array}$ & $\begin{array}{c}73.6 \\
8.6 \\
9 \\
>0.2\end{array}$ \\
\hline
\end{tabular}

potential in the "intact" arm fell well below the normal range. When the partially-amputated (PA) sides were studied, the compound action potentials
A
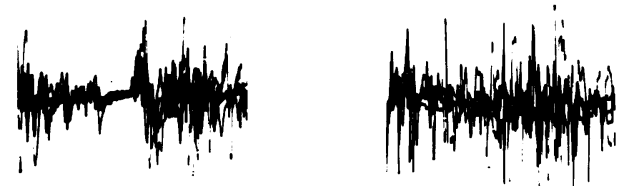

$\mathbf{B}$
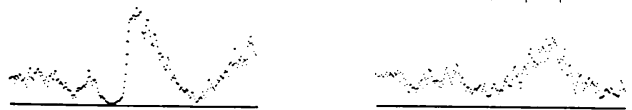

c

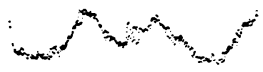

D
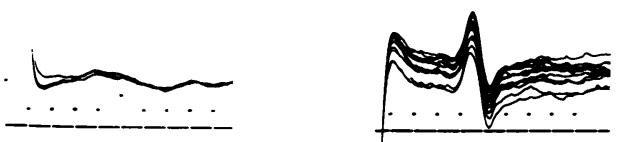

Fig. 2 Responses after maximal stimulation of the ulnar nerve in the distal part of the forearm of the intact (right) and PA arms (left) of patient SK. Stimuli delivered at the onset of recording. A: superimposed traces of volitional activity in ipsilateral triceps muscle. $B$ : triceps activity after rectification and averaging. $C$ : evoked responses in contralateral somatosensory cortex. D: compound action potential at elbow. Negativity of stigmatic electrode shown as upward deflection. Vertical bar represents $40 \mu \mathrm{V}, 10 \mu \mathrm{V}$, and $20 \mu V$ for $A, C$, and D respectively. Smallest intervals on time calibration equal $1 \mathrm{~ms}(D)$ and $20 \mathrm{~ms}(A, B$, and $C$ ).

were markedly reduced in amplitude, the mean value being only $8 \mu \mathrm{V}$ and the range 3 to $25 \mu \mathrm{V}$ (Fig. 1). Similar discrepancies between the intact and PA sides were observed in the patient in whom recordings were made from the supraclavicular fossa, after ulnar nerve stimulation, and in one patient in whom the median nerve was also examined. An example of the reduction in amplitude of the action potential on the side of the amputation is given in Fig. 2D. In this patient it can be seen that the response in the PA limb was dispersed in relation to the control recording, the intervals between the onsets and terminations of the negative waves being 3.9 and $1.4 \mathrm{~ms}$ respectively. This degree of temporal dispersion was exceptional for in other patients the extra duration of the negative component did not exceed $50 \%$ of the control value, the mean increase being $24 \%$.

In contrast to the measurements of potential amplitude, the impulse conduction velocities were reduced to lesser extents in the PA limbs (Fig. 1). This reduction became statistically significant when the population of normal subjects was used for comparison (Table 2). 


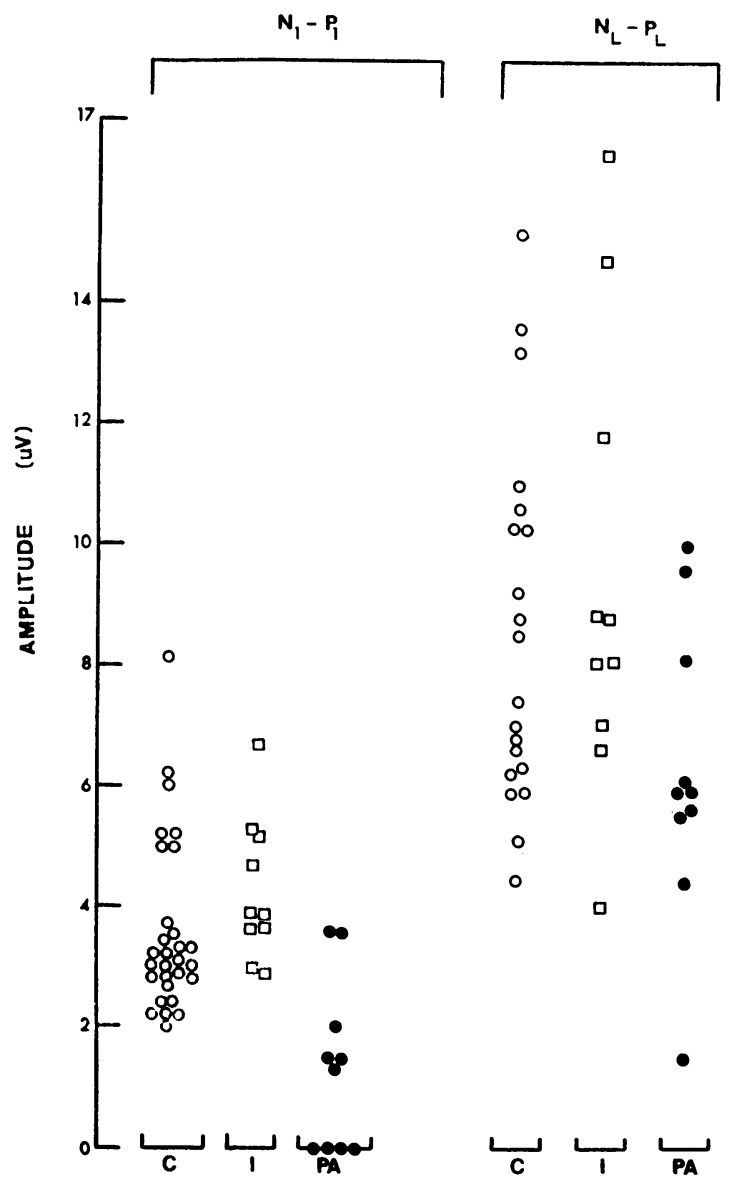

Fig. 3 Amplitudes of early $\left(N_{1}-P_{1}\right)$ and later $\left(N_{\mathrm{L}}-P_{\mathrm{L}}\right)$ components of contralateral somatosensory cortical responses after maximal stimulation of ulnar nerves. Symbols as for Fig. 1. C: results for control subjects; $P A, I$ : results from stimulation of $P A$ and intact limbs of patients respectively.

\section{CORTICAL EVOKED RESPONSES}

When a normal ulnar nerve was stimulated maximally below the elbow a response could be recorded over the contralateral somatosensory cortex with a latency of 15 to $20 \mathrm{~ms}$ (mean $17.0 \pm 1.5 \mathrm{~ms}$ ). The response consisted of a small brief negative wave which was succeeded by alternating positive and negative potentials of larger amplitude. The amplitudes of two components in the response were measured. One component consisted of the deflection from the crest of the initial negative wave $\left(N_{1}\right)$ to that of the earliest positive potential $\left(P_{1}\right)$; this deflection comprises the $N_{1}$ and $P_{1}$ potentials of Desmedt et al. (1973) and corresponds to the first component of Allison (1962). The other
Table 3 Amplitudes of early and late components of control somatosensory cortical responses after maximal stimulation of ulnar nerves (see text). Middle section of table gives latencies of $N_{1}$ components. Nomenclature and statistical treatment as for Table 2

\begin{tabular}{|c|c|c|c|c|c|c|}
\hline & & \multicolumn{3}{|c|}{ Controls } & \multicolumn{2}{|c|}{ Patients } \\
\hline & & $R$ & $L$ & $R+L$ & $P A$ & $I$ \\
\hline $\begin{array}{l}\mathbf{N}_{1}-\mathbf{P}_{1} \\
\text { Component }(\mu \mathrm{V})\end{array}$ & $\begin{array}{l}\bar{x} \\
S D \\
n \\
p\end{array}$ & $\begin{array}{l}4.0 \\
2.0 \\
15\end{array}$ & $\begin{array}{l}3.8 \\
1.6 \\
15\end{array}$ & $\begin{array}{l}3.9 \\
1.8 \\
30\end{array}$ & $\begin{array}{l}1.4 \\
1.4 \\
10 \\
<0.001\end{array}$ & $\begin{array}{l}4.3 \\
1.2 \\
10 \\
>0.2\end{array}$ \\
\hline $\begin{array}{l}\mathrm{N}_{1} \text { Component } \\
\text { (ms) }\end{array}$ & $\begin{array}{l}\bar{x} \\
\text { SD } \\
n \\
p\end{array}$ & $\begin{array}{c}17.2 \\
1.3 \\
15\end{array}$ & $\begin{array}{c}16.9 \\
1.8 \\
15\end{array}$ & $\begin{array}{c}17.0 \\
1.5 \\
30\end{array}$ & $\begin{array}{c}18.2 \\
2.3 \\
6 \\
>0.2\end{array}$ & $\begin{array}{l}17.7 \\
1.3 \\
10 \\
>0.1\end{array}$ \\
\hline $\begin{array}{l}\mathrm{N}_{\mathrm{L}}-\mathrm{P}_{\mathrm{L}} \\
\text { Component }(\mu \mathrm{V})\end{array}$ & $\begin{array}{l}\bar{x} \\
S D \\
n \\
p\end{array}$ & $\begin{array}{l}8.4 \\
2.3 \\
15\end{array}$ & $\begin{array}{l}9.2 \\
3.2 \\
15\end{array}$ & $\begin{array}{l}8.8 \\
2.8 \\
30\end{array}$ & $\begin{array}{l}6.2 \\
2.5 \\
10 \\
<0.01\end{array}$ & $\begin{array}{l}9.4 \\
3.8 \\
10 \\
>0.5\end{array}$ \\
\hline
\end{tabular}

measurement of amplitude was made from the peak of the next (main) negative wave to that of the largest of the later positive waves. The latter can be clearly identified in the lower trace in Fig. 2B, but is less obvious in the upper record. Since it was difficult to classify these later potentials according to Allison's scheme, they have been simply referred to as the "late" negative and positive waves $\left(\mathrm{N}_{\mathrm{L}}\right.$ and $\mathrm{P}_{\mathrm{I}}$ respectively).

In the control subjects there were no consistent differences between the $\mathrm{N}_{1}-\mathrm{P}_{1}$ responses on the two sides, the mean values for the right and left sides being similar (4.0 and $3.8 \mu \mathrm{V}$ respectively; Table 3). Although the amplitudes of the 30 control limbs showed a greater than threefold range $(2.2$ to $8.1 \mu \mathrm{V})$, there was good agreement between the responses on the two sides of individual subjects (mean difference $=12.0 \pm 10.4 \%$ of smaller value). The $N_{L}-P_{L}$ response also varied from subject to subject (range 4.4-15.1 $\mu \mathrm{V}$ ) but showed reasonable correspondence between the two sides of individual subjects (mean difference, 17.9 \pm $11.3 \%$ of smaller value); it was, however, substantially larger than the $\mathbf{N}_{1}-\mathbf{P}_{1}$ component (the mean amplitude being $8.8 \pm 2.8 \mu \mathrm{V})$. When the intact limbs of the amputees were studied the $N_{1}-P_{1}$ and $N_{L}-P_{L}$ deflections, recorded over the contralateral hemispheres, had amplitudes similar to the corresponding potentials in controls (Table 3).

When the ulnar nerves in the PA limbs were stimulated the cortical evoked responses differed from the control observations in having significantly smaller $\mathrm{N}_{1}-\mathrm{P}_{1}$ components (mean 1.4士 $1.4 \mu \mathrm{V}$ ). In four patients, including the one whose results are shown in Fig. 2, it was not possible to 
discern an early component at all, while in the remaining six the responses were smaller on the side of the head opposite to the amputation (Fig. 3). Although the latencies of these abnormal responses tended to be slightly longer than the control responses, the mean difference was not significantly different (Table 3 ). In contrast to the earlier deflection, the $N_{L}-P_{L}$ response was better proserved contralateral to the amputation and could be detected in every patient, the mean value being $6.2 \pm 2.5 \mu \mathrm{V}$ (range 1.4 to $11.4 \mu \mathrm{V}$ ); this value was nevertheless significantly less than the control mean (Table 3).

\section{TRICEPS RESPONSES}

Electrical stimulation of the skin or of a cutaneous nerve affects the excitability of motoneurones innervating the same limb, the pattern of motor unit response depending on the muscle and sensory nerve selected for study (Hagbarth, 1952; Caccia et al., 1973). Similarly, pronounced reflex effects have long been known to follow stimulation of sensory fibres emanating from receptors in the muscles spindles and Golgi tendon organs. In the present study, repeated maximal stimuli were applied to the ulnar nerve below the elbow but no attempt was made to identify the contributions

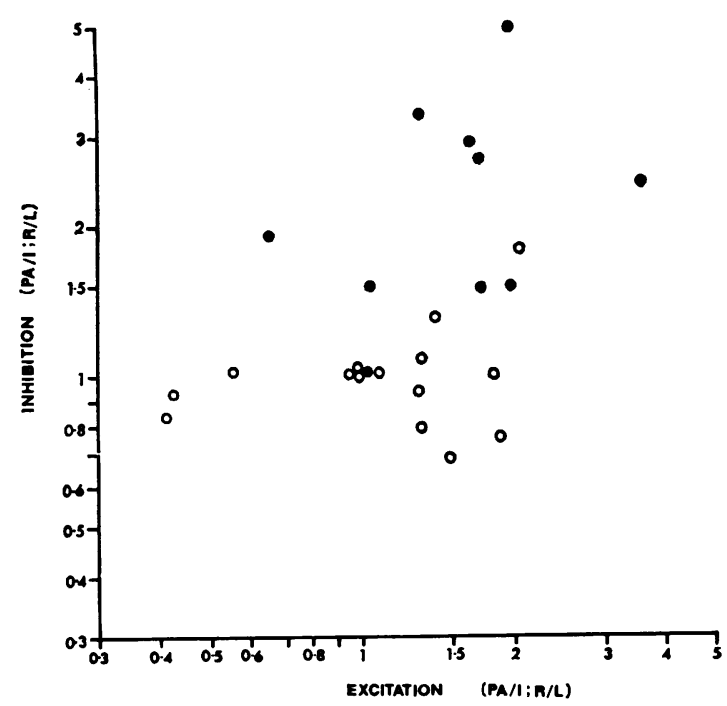

Fig. 4 Symmetry of excitation and inhibition in triceps motor units. For each control subject the excitatory or inhibitory value for the right arm has been divided by the corresponding result for the left arm. For patients, the value for the PA limb has been expressed in terms of the "intact" limb. Asymmetry is indicated by values other than unity. Symbols as for Fig. 1.
Table 4 Extent of excitation and inhibition in triceps motor units after maximal stimulation of ipsilateral ulnar nerve. Nomenclature and statistical treatment as for Table 2

\begin{tabular}{|c|c|c|c|c|c|c|}
\hline & & \multicolumn{3}{|c|}{ Controls } & \multicolumn{2}{|c|}{ Patients } \\
\hline & & $\boldsymbol{R}$ & $L$ & $R+L$ & $P A$ & $I$ \\
\hline $\begin{array}{c}\text { Inhibition } \\
(\%)\end{array}$ & $\begin{array}{l}\overline{\mathbf{x}} \\
\mathbf{S D} \\
\mathbf{n} \\
\mathbf{p}\end{array}$ & $\begin{array}{l}74.3 \\
14.8 \\
15\end{array}$ & $\begin{array}{l}76.4 \\
19.5 \\
15\end{array}$ & $\begin{array}{l}75.4 \\
17.0 \\
30\end{array}$ & $\begin{array}{l}79.7 \\
25.9 \\
10 \\
>0.5\end{array}$ & $\begin{array}{l}41.8 \\
25.7 \\
10 \\
<0.001\end{array}$ \\
\hline $\begin{array}{c}\text { Excitation } \\
(\%)\end{array}$ & $\begin{array}{l}\overline{\mathbf{x}} \\
\text { SD } \\
\mathbf{n} \\
\mathbf{p}\end{array}$ & $\begin{array}{l}48.8 \\
27.5 \\
15\end{array}$ & $\begin{array}{l}47.8 \\
29.0 \\
15\end{array}$ & $\begin{array}{l}46.6 \\
26.0 \\
30\end{array}$ & $\begin{array}{l}68.4 \\
51.1 \\
10 \\
>0.2\end{array}$ & $\begin{array}{l}42.8 \\
20.9 \\
10 \\
>0.5\end{array}$ \\
\hline
\end{tabular}

of different types of sensory fibre. During the period of stimulation the subject attempted to maintain a steady contraction of the triceps muscle against resistance; the elbow joint was maintained at approximately $90^{\circ}$ and the contraction was of moderate intensity. In 24 of the 28 normal limbs studied in controls the effect of ulnar nerve stimulation was to produce a period of inhibition beginning at approximately $40 \mathrm{~ms}$ after the stimulus and with a duration of up to $70 \mathrm{~ms}$ (Fig. 2). In four of the 30 control limbs the inhibition was temporarily complete. In all the control subjects displaying inhibition a subsequent phase of enhanced motor unit excitability was observed, beginning at approximately $110 \mathrm{~ms}$ after the stimulus.

A rough comparison of the respective amounts of inhibition and excitation on the two sides was made from the averaged recording of the rectified EMG activity in the triceps muscle (see Methods). Considerable variation was found in the extent of inhibition and excitation between control subjects, but, for inhibition at least, the results in any one subject were reasonably symmetrical (Fig. 4).

The results in the 10 patients differed in that inhibition and excitation were nearly always more prominent on the side of amputation (Fig. 4). Although in five of the 10 amputated limbs the inhibition was complete, inspection of Table 4 shows that the reason for the discrepancies between the two sides was that inhibition was significantly less than normal on the intact side; in contrast, excitation tended to be enhanced on the side of the lesion, though not significantly so.

\section{Discussion}

Since the observations of Bérard (1829) there has been general agreement that macroscopic change can be detected in the spinal cords of patients who have undergone amputation but there has been dispute as to their anatomical extent and cellular 
nature. The pathological findings in the early investigations in man and animals have been comprehensively reviewed by Ranson (1906) and Barratt (1901), and need not be repeated in detail here. It is sufficient to say that some workers have claimed that only the grey matter of the ipsilateral anterior horn becomes atrophied while others have incriminated either the posterior horn alone or both horns. Again, while the atrophy appears to be associated with a loss of neurones in some studies, in others it was attributed to shrinkage of cells. Similar disagreement concerns the degree of atrophy in the anterior and posterior roots, and of the long ascending and descending tracts within the cord. Relevant electrophysiological studies have been comparatively recent and have dealt with the central effects of peripheral nerve or dorsal root section in animals. For example, in cats Mendell et al. (1976) (see also Eccles et al., 1959) have studied synaptic potentials in axotomised motoneurones, while Wall and colleagues have investigated the early and late functional changes in the gracile nucleus after dorsal rhizotomy (Dostrovsky et al., 1976; Millar et al., 1976). In the present study we have made three types of observation after stimulation of the nerve stump: (a) impulse conduction in the divided fibres, (b) reflex effects on intact motoneurones, and (c) cortical somatosensory evoked responses.

\section{PERIPHERAL NERVE RECORDINGS}

The most obvious feature of the compound action potential recorded from the peripheral nerve stump was the striking reduction in its amplitude when compared with results on the normal side. This reduction amounted to almost $90 \%$ when the mean values for the normal and amputated sides were compared. That there was no correlation with the duration of the nerve severance in the present study suggested that most of the change had occurred before the earliest of the present observations (two years after injury). Serial studies, starting immediately after amputation, would be necessary to confirm this deduction. Although some of the reduction in response amplitude may have been due to impulse dispersion (see Results and Devor and Wall, 1976), the magnitude of the attenuation suggests that there may also have been losses of excitable fibres in the nerve stumps. That some of the surviving fibres are sensory is evident from their ability to cause reflex activity in triceps motoneurones and to evoke responses in the somatosensory cortex. The proportion of these fibres in the surviving population was not determined and it is not clear whether function was preserved in any $a$-motor fibres; single unit records (Vallbo and Hagbarth, 1968) from the nerve stump would obviously be informative. So great was the loss of excitability, however, that it must have involved cutaneous and propioceptive sensory fibres as well as motor ones. It is also evident that the loss of excitability far exceeded the proportion of axons which have been observed to undergo retrograde degeneration, as judged with the light microscope, after nerve section in mammals (Ranson, 1906; Bucy, 1928; Kiraly and Krnjevíc, 1959).

In relation to impulse conduction velocity, we found a slight reduction in surviving fibres, confirming most previous observations (Eccles et al., 1959; Kiraly and Krnjevíc, 1959; Cragg and Thomas, 1961).

SOMATOSENSORY EVOKED CORTICAL RESPONSES

The components of the response which can be recorded from the scalp overlying the contralateral somatosensory cortex in man in the first $200 \mathrm{~ms}$ after peripheral nerve stimulation are mediated by the dorsal column-medial lemniscus pathway (Halliday and Wakefield, 1963; Giblin, 1964). In the present study the components identified as the $\mathrm{N}_{1}-\mathrm{P}_{1}$ deflection were significantly diminished, after stimulation of PA limbs, in comparison with responses evoked by excitation of normal peripheral nerves. It was possible that the reduction in response was entirely due to the profound loss of conducting sensory fibres demonstrated in this study. However, in additional experiments in which the nerve volley on the normal side was reduced to match that on the amputated side, the early cortical components were still comparatively reduced contralateral to the lesion. These last observations suggested that there may have been degeneration in the dorsal column pathway; such degeneration has been observed in some of the anatomical studies (Barratt, 1901).

Although later parts of the somatosensory cortical evoked response were also diminished contralateral to the amputation, the reduction was much less than that of the earlier components. This discrepancy might have meant that there had been less degeneration in rostrally situated neurones in the dorsal column-medial lemniscal pathway, but it might also have reflected the steeper rise of the input-output curve for the later components of the cortical response (unpublished observations).

\section{REFLEX STUDIES}

Rather surprisingly, reflex modulation of activity in triceps motoneurones could be readily demonstrated in amputated limbs, even though fewer sensory fibres had been activated by the maximal 
stimuli than in the intact limbs. It is possible that spontaneous impulse activity arising in neuromata (Wall and Gutnick, 1974) may have helped to maintain effective synaptic connections within the polysynaptic pathways responsible for these reflexes. A quite unexpected finding was that inhibition was significantly diminished in the "intact" arms of our patients. Since it has not been possible to demonstrate any contralateral reflex effects on triceps motor units after peripheral nerve stimulation in normal subjects, it seems unlikely that the changes on the intact side are secondary to loss of a tonic inhibitory influence from the partially amputated limb. A more attractive possibility is that excessive use of the intact arm, after contralateral amputation, modifies the effectiveness of certain synaptic pathways. In keeping with this suggestion is the observation by Eccles and McIntyre (1953), that monosynaptic reflex activity in extensor motoneurones of cats is enhanced in segments of spinal cord adjacent to those affected by dorsal rhizotomy; these authors postulated that increased usage was responsible.

Two further points deserve mention. Of the 10 patients studied, the one who gave the least abnormal results was a 19 year old man with a congenital absence of the forearm and hand. Although it is dangerous to speculate from a single observation, it seems possible that the congenital absence of target tissue (skin and muscle) may have less damaging consequences for the central nervous system than the deprivation of previously innervated structures. Finally, the severe loss of conducting motor axons after amputation must be taken into account in attempts to use efferent impulses in the nerve stump as a triggering mechanism for movements in a limb prosthesis ( $c f$. Mannard et al., 1974).

We are grateful to Dr J. Delbeke for assistance in one of the experiments. Henny Farenhorst and Glenn Shine made their technical expertise available while Norma Zimmerman provided secretarial assistance. Financial support was received from the Canadian Medical Research Council through its grant to the Research Group in Developmental Neurobiology.

\section{References}

Allison, T. (1962). Recovery functions of somato sensory evoked responses in man. Electroenciphalography and Clinical Neurophysiology, 14, 331-343.

Barratt, J. O. W. (1901). On the changes in the nervous system in a case of old-standing amputation. Brain, 24, 310-328.
Bérard (1829). Bulletins de la Société Anatomique de Paris, no. 3, Cited by Ranson, S. W. in Journal of Comparative Neurology, 16, 265-203 (1906).

Bucy, P. C. (1928). Studies in degeneration of peripheral nerves. Journal of Comparative Neurology, 45, $129-159$.

Caccia, M. R., McComas, A. J., Upton, A. R. M., and Blogg, T. (1973). Cutaneous reflexes in small muscles of the hand. Journal of Neurology, Neurosurgery, and Psychiatry, 36, 960-977.

Cragg, B. G., and Thomas, P. K. (1961). Changes in conduction velocity and fibre size proximal to peripheral nerve lesions. Journal of Physiology, 157, 315-327.

Desmedt, J. E., Noël, P., Debecker, J., and Namèche, J. (1973). Maturation of afferent conduction velocity as studied by sensory nerve potentials and by cerebral evoked potentials. In New Developments in Electromyography and Clinical Neurophysiology, vol. 2, pp. 52-63. Edited by J. E. Desmedt. Karger: Basel.

Devor, M., and Wall, P. D. (1976). Type of sensory nerve fibre sprouting to form a neuroma. Nature, 262, 705-707.

Dostrovsky, J. O., Millar, J., and Wall, P. D. (1976). The immediate shift of afferent drive of dorsal column nucleus cells following deafferentation: a comparison of acute and chronic deafferentation in gracile nucleus and spinal cord. Experimental Neurology, 52, 480-495.

Drachman, D. B. (1974). Trophic Functions of the Neuron. Annals of the New York Academy of Sciences, 228, 423 p.

Eccles, J. C., Krnjevic, K., and Miledi, R. (1959). Delayed effects of peripheral severance of afferent nerve fibres on the efficacy of their central synapses. Journal of Physiology, 145, 204-220.

Eccles, J. C., and McIntyre, A. K. (1953). The effects of disuse and of activity on mammalian spinal reflexes. Journal of Physiology, 121, 492-516.

Giblin, D. R. (1964). Somatosensory evoked potentials in healthy subjects and in patients with lesions of the nervous system. In Sensory Evoked Response in Man. Edited by R. Katzman. Annals of the New York Academy of Sciences, 112, 93-142.

Hagbarth, K.-E. (1952). Excitatory and inhibitory skin for flexor and extensor motoneurones. Acta Physiologica Scandinavica, 26, Suppl. 94, 58p.

Halliday, A. M., and Wakefield, G. S. (1963). Cerebral evoked potentials in patients with dissociated sensory loss. Journal of Neurology, Neurosurgery, and Psychiatry, 26, 211-219.

Kiraly, J. K., and Krnjevíc, K. (1959). Some retrograde changes in function of nerves after peripheral section. Quarterly Journal of Experimental Physiology, 44, 244-257.

McComas, A. J., Sica, R. E. P., and Banerjee, S. (1978). Central nervous system effects of limb amputation in man. Nature, 271, 73-74.

Mannard, A., Stein, R. B., and Charles, D. (1974). Regeneration electrode units: implants for recording 
from peripheral nerve fibres in freely moving animals. Science, New York, 183, 547-591.

Mendell, L. M., Munson, J. B., and Scott, J. G. (1976). Alterations of synapses on axotomised motoneurones. Journal of Physiology, 255, 67-79.

Millar, J., Basbaum, A. I., and Wall, P. D. (1976). Restructuring of the somatotopic map and appearance of abnormal neuronal activity in the gracile nucleus after partial deafferentation. Experimental Neurology, 50, 658-672.

Ranson, S. W. (1906). Retrograde degeneration in the spinal nerves. Journal of Comparative Neurology, 16, 265-293.

Vallbo, A. B., and Hagbarth, K.-E. (1968). Activity from skin mechanoreceptors recorded percutaneously in awake human subjects. Experimental Neurology, 21, 370-389.

Wall, P. D., and Gutnick, M. (1974). Ongoing activity in peripheral nerves: the physiology and pharmacology of impulses originating from a neuroma. Experimental Neurology, 43, 580-593. 